\title{
Development, Testing, and Failure Mechanisms of a Replicative Ice Phase Change Material Heat Exchanger
}

\author{
Thomas O. Leimkuehler ${ }^{1}$ \\ Paragon Space Development Corporation, Houston, Texas, 77058 \\ Scott Hansen ${ }^{2}$ \\ Texas A\&M University, College Station, Texas, 77843 \\ and \\ Ryan A. Stephan ${ }^{3}$ \\ NASA-Johnson Space Center, Houston, Texas, 77058
}

\begin{abstract}
Phase change materials (PCM) may be useful for thermal control systems that involve cyclical heat loads or cyclical thermal environments such as Low Earth Orbit (LEO) and Low Lunar Orbit (LLO). Thermal energy can be stored in the PCM during peak heat loads or in adverse thermal environments. The stored thermal energy can then be released later during minimum heat loads or in more favorable thermal environments. One advantage that PCM's have over evaporators in this scenario is that they do not use a consumable. Wax PCM units have been baselined for the Orion thermal control system and also provide risk mitigation for the Altair Lander. However, the use of water as a PCM has the potential for significant mass reduction since the latent heat of formation of water is approximately $70 \%$ greater than that of wax. One of the potential drawbacks of using ice as a PCM is its potential to rupture its container as water expands upon freezing. In order to develop a space qualified ice PCM heat exchanger, failure mechanisms must first be understood. Therefore, a methodical experimental investigation has been undertaken to demonstrate and document specific failure mechanisms due to ice expansion in the PCM. An ice PCM heat exchanger that replicates the thermal energy storage capacity of an existing wax PCM unit was fabricated and tested. Additionally, methods for controlling void location in order to reduce the risk of damage due to ice expansion are investigated. This paper presents the results to date of this investigation.
\end{abstract}

$\begin{array}{ll}C_{p} & =\text { specific heat of the coolant } \\ C_{p, i} & =\text { Nomecific heat of heat exchanger component } i \\ E & =\text { energy storage requirement } \\ E_{l} & =\text { latent energy storage } \\ E_{s} & =\text { sensible energy storage } \\ E_{t} & =\text { total energy storage } \\ H_{f} & =\text { latent heat of formation } \\ L E O & =\text { low earth orbit } \\ L L O & =\text { low lunar orbit } \\ m_{i} & =\text { mass of heat exchanger component } i \\ \dot{m} & =\text { mass flow rate } \\ P C M & =\text { phase change material } \\ P G W & =\text { propylene glycol water }\end{array}$

${ }_{1}^{1}$ Senior Aerospace Engineer, 1120 NASA Parkway, Suite 505, Non-member.
2 Student, Department of Mechanical Engineering, 3123 TAMU, Non-member.
${ }^{3}$ Thermal Engineer, Crew and Thermal Systems Division, 2101 NASA Parkway, M/S EC1, Non-member.

American Institute of Aeronautics and Astronautics 


$\begin{array}{ll}Q & =\text { instantaneous heat rate into/from the heat exchanger } \\ R I P & =\text { replicative ice PCM } \\ \text { SHReD } & =\text { supplemental heat rejection device } \\ \text { SHRIMP } & =\text { small heat sinks of replicative ice material for phase change } \\ t_{0} & =\text { time at the beginning of a test point } \\ t_{f} & =\text { time at the conclusion of a test point } \\ T_{\text {in }} & =\text { inlet temperature of the coolant } \\ T_{\text {initial }, i} & =\text { initial steady-state temperature of heat exchanger component } i \\ T_{\text {final, } i} & =\text { final steady-state temperature of heat exchanger component } i \\ T_{\text {out }} & =\text { outlet temperature of the coolant }\end{array}$

\section{Introduction}

WASA has developed the Constellation program in response to the Vision for Space Exploration. The Constellation program is chartered with developing the space architecture for returning humans to the Lunar surface. The myriad challenges associated with this mission require technology development in several technical disciplines. Current operations of the Orion vehicle will require the spacecraft to orbit the moon in Low Lunar Orbit (LLO) for up to six months. As shown in Fig. 1, the lunar surface temperature varies from approximately 400 Kelvin to less than 100 Kelvin. The hottest portion of the lunar surface corresponds to the point directly aligned with the sun. Similarly, the coldest portion corresponds to the point directly on the opposite side of the moon. As a result of this large variation in Lunar surface temperature, the vehicle will experience large changes in the radiative thermal environment caused by the changing infrared heat load incident on the vehicle.

Because of the large changes in radiative sink temperature, heat rejection devices must be able to meet the requirement for both hot and cold parts of the orbit or a combination of heat rejection devices must be used to meet the vehicle's requirement. Figure 2 shows an example of the variability of a vehicle's heat rejection capability using only radiators for a $100 \mathrm{~km}$ circular orbit with a beta angle of zero degrees. From a thermal perspective, a beta zero orbit represents the worst case hot LLO environment. As shown in this figure, the radiators are capable of rejecting the full vehicle heat load for the majority of the orbit period. However, when the vehicle is situated above or near the subsolar point, the radiator capability is less than the vehicle requirement ( 0 to 0.4 hours and 1.6 to 2 hours). During this period of time, a Supplemental Heat Rejection Device (SHReD) is required to meet the vehicle's heat rejection requirement. The function of the SHReD can be achieved using either evaporators or Phase Change Material heat sinks.

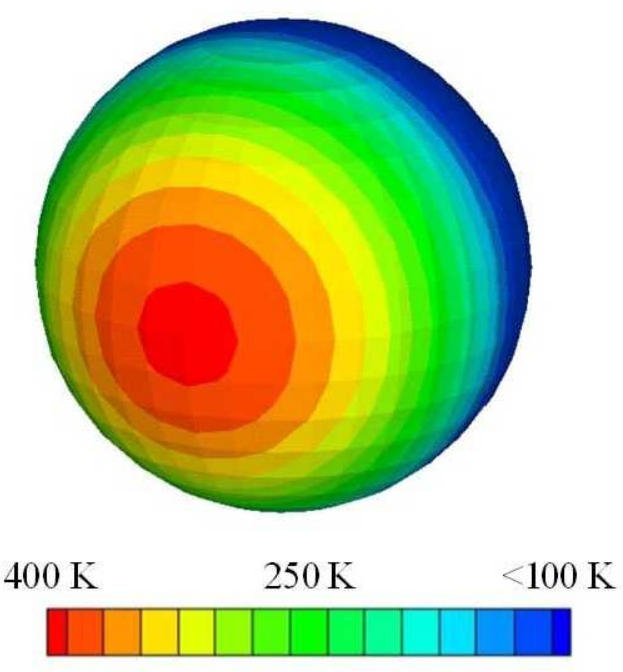

Figure 1. Lunar surface temperatures. 


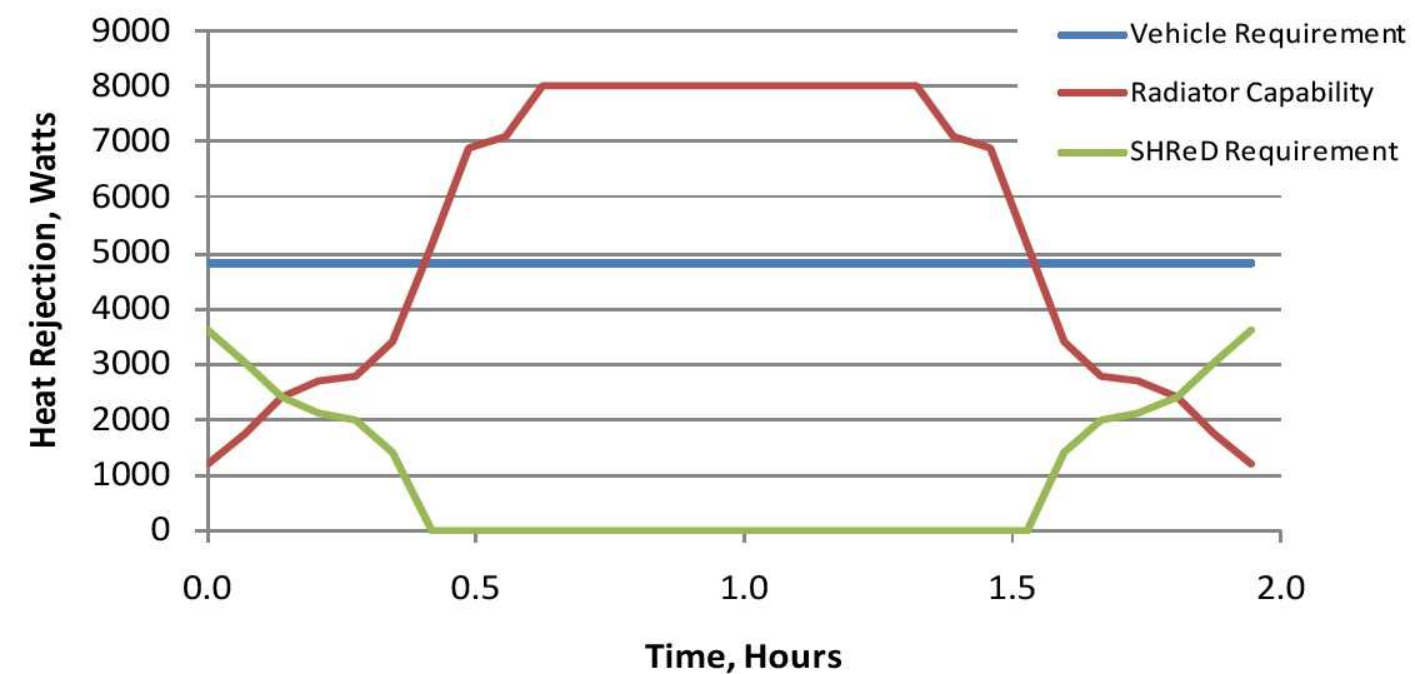

\section{Figure 2. SHReD Requirements}

Phase Change Material heat exchangers are used to store excess thermal energy during periods of high heat loads or warm thermal environments by melting the phase change material internal to the heat exchanger. During periods of reduced load or colder thermal environment, the material is refrozen, preparing it for the next thermal cycle. As implied by the name, evaporators evaporate a consumable fluid and reject the resulting vapor to space. Using a PCM heat sink as a SHReD can be advantageous for long mission durations because it does not require a consumable evaporant.

The mass required for a given energy rejection requirement is shown in Equation 1. For a given energy storage requirement the amount of mass required is inversely proportional to the enthalpy change of the material being used for heat rejection/storage. For an evaporator, this change in enthalpy is the heat of vaporization $(2500 \mathrm{~kJ} / \mathrm{kg}$ for water). For a PCM heat sink, on the other hand, the change is represented as the heat of fusion $(333 \mathrm{~kJ} / \mathrm{kg})$. While evaporators appear to be more mass efficient for a given energy storage requirement, it is important to remember that they require a consumable. For Orion's application, which is a six-month mission and includes almost 2200 thermal cycles, a PCM heat sink is much more mass efficient.

$$
\text { Mass }=\frac{E}{H_{f}}
$$

The current baseline PCM for Orion is n-pentadecane ${ }^{1}$, a type of paraffin wax, but the project is investigating the use water as a PCM due to water's significantly higher heat of fusion. Equation (1) can also be used to compare two separate phase change materials. A PCM with a high heat of fusion is desirable as it will reduce the mass of the vehicle's SHReD. The heat of fusion for n-pentadecane is approximately $200 \mathrm{~kJ} / \mathrm{kg}$ whereas the heat of fusion for water is $333 \mathrm{~kJ} / \mathrm{kg}$ as mentioned above. The use of water as the phase change material has the potential to reduce the heat exchanger mass by approximately $70 \%$.

The use of water is not without challenges, however. Unlike most materials, water expands as it freezes leading to concerns regarding structural integrity of the hardware. The objective of the current task is to assess the feasibility of replacing the commonly used paraffin-based material with water to realize the potential mass benefits associated with this change.

\section{Test Articles}

Three test articles were designed, fabricated, and delivered to NASA JSC. One objective of the subsequent test program was to demonstrate feasibility of using water as the phase change material. An additional objective was to use the test articles to better understand the technical issues associated with the expansion of water within a PCM heat sink. 
The first test article, Replicative Ice PCM (RIP), consists of an off-the-shelf coldplate (Lytron CP-30) and included a total of 1360 grams of water as the phase change material. The coldplate was 0.75 inches thick and included a finned "u-shape" passage for the coolant. The mounting surface area was approximately 7.8 " by 11 " and PCM modules were attached to both sides of the coldplate. The PCM modules included a carbon fibercore structure to enhance the thermal conductance across the module. The fibercore structure is shown in Fig. 3.

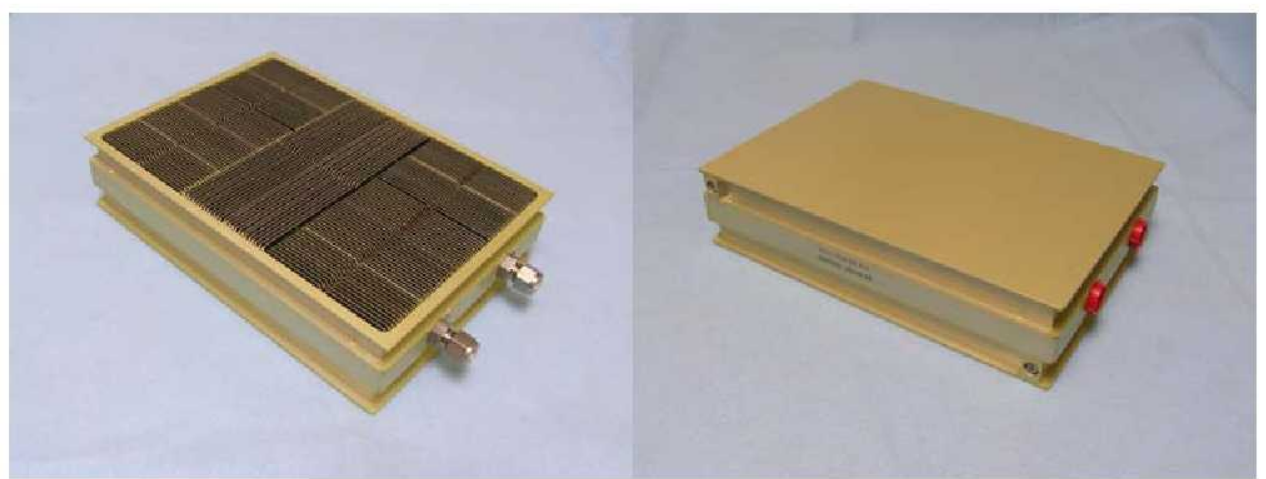

Figure 3. Replicative Ice PCM (RIP) test article showing the internal carbon fibercore structure (left) and the final configuration (right).

As the name implies, the Replicative Ice PCM was designed to replicate the latent heat storage capacity of existing paraffin-based PCM heat exchangers that were baselined for use on Orion. In an effort to closely match the design of the baseline units, RIP included the same off-the-shelf coldplates and interstitial material construction. The only difference between the two units was the phase change material. Because water has a much higher heat of fusion as compared to n-pentadecane (paraffin material used for the baseline heat exchanger), RIP was both smaller and lighter than the baseline paraffin unit. The RIP mass was $118.6 \mathrm{~g}$ while the baseline heat exchanger mass was $184.3 \mathrm{~g}$. Additionally, the volume of RIP was approximately $47 \%$ less than the paraffin heat sink. Figure 4 shows a side-by-side comparison of RIP and the paraffin wax unit.

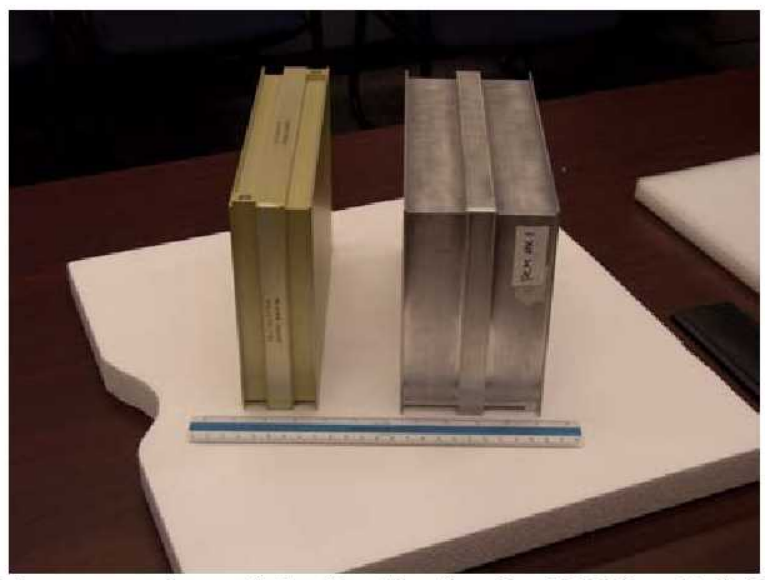

Figure 4. Side by side comparison of the Replicative Ice PCM unit (left) and a paraffin wax PCM unit (right). Each unit has the same latent thermal storage capacity of $450 \mathrm{~kJ}$.

Because the project was concerned with the aforementioned expansion of ice, a simple air gap was included in the design to accommodate the expansion. This air gap was approximately $20 \%$ of the height of the PCM modules located on either side of the coldplate. It is acknowledged that including a simple air gap may not provide a solution that is robust enough, especially for a microgravity application,. However, this project is taking an approach of starting with the simplest potential solution to investigate first, and then working toward more complex solutions if needed.

The second test article, referred to as SHRIMP-1, was fabricated using the same Lytron CP-30 coldplate included in the RIP design. SHRIMP-1 was designed to serve as a smaller, more cost efficient version of the replicative ice PCM. This test article would serve as a baseline unit for future ice PCM development efforts. 
SHRIMP-1 had an expected latent energy storage of approximately $40 \mathrm{~kJ}$ and therefore included 120 grams of water as the phase change material. The interstitial material construction was the same as RIP. As was the case with RIP, SHRIMP-1 included a $20 \%$ air gap for the purpose of accommodating the expansion of water upon freezing.

The third, and final, test article was the project's second (and more refined) attempt to include intelligent void control in the heat sink design. The latent energy for SHRIMP-2 was also $40 \mathrm{~kJ}$ and it was the same size as SHRIMP-1 as shown in Fig. 5.

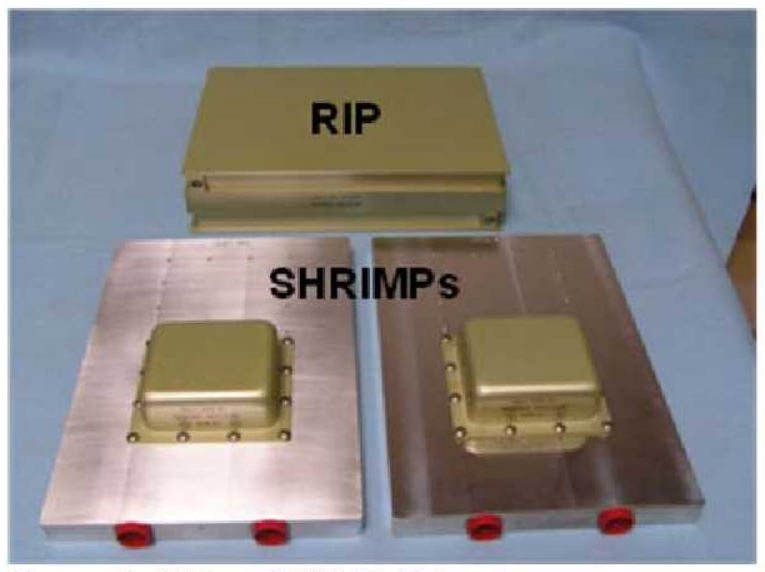

Figure 5. RIP and SHRIMP hardware.

As before, this test article was only filled to approximately $80 \%$ of its total volume. The difference was in the construction of the interstitial material structure as detailed in Figs. 6 and 7.

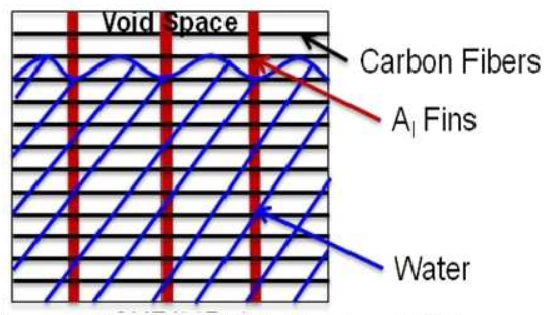

Figure 6. SHRIMP-1 interstitial configuration.

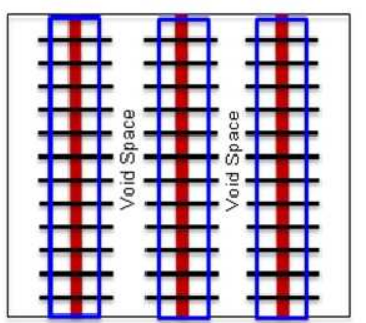

Figure 7. SHRIMP-2 interstitial configuration.

The preceding figures show a conceptual image detailing the interstitial material configuration differences between SHRIMP-1 and SHRIMP-2. This figure shows the aluminum fins and the carbon fibers, the water phase change material, and the location of the $20 \%$ void within the PCM module. In Fig. 6 , the water is shown at the bottom of SHRIMP-1 and the void space is shown near the top. If capillary effects dominate gravity effects, there is no preferred location of water and voids. In fact, the water and the void space may be randomly distributed. In this case a situation could occur where the freezing water is unable to "reach" the void space when necessary. SHRIMP2 was designed to address this situation. In this design, the carbon fibers do not intersect with other carbon fibers located on adjacent aluminum fins. In this arrangement, carbon fibers wick up water so that it is located top-tobottom in the PCM module. This creates void space between the aluminum fins instead of randomly located or at the top of the PCM module.

A summary of the three previously described test articles is presented in Table 1. 
Table 1. Summary of test articles.

\begin{tabular}{|l|c|c|c|}
\hline \multicolumn{1}{|c|}{ Test Article } & Expected Latent Storage (kJ) & PCM Mass (g) & Other Notes \\
\hline Wax-PCM & 450 & 2772 & Baseline for Orion \\
\hline RIP & 450 & 1360 & \\
\hline SHRIMP-1 & 40 & 120.1 & Fins arranged like RIP (Fig. 6) \\
\hline SHRIMP-2 & 40 & 120.2 & Unique fin arrangement (Fig. 7) \\
\hline
\end{tabular}

\section{Test Set-Up}

The ice PCM test cart was designed to accommodate up to four test articles (see Fig. 8). The test cart consists of two chiller carts arranged to provide both a hot loop and a cold loop, which were used to thaw and freeze the phase change material, respectively. A mixture of propylene glycol and water was used as the working fluid in each of the pumped fluid loops. Test article flow rates could be varied by computer control or by adjusting isolation valves located immediately upstream and downstream of the test articles as shown in Fig. 8. Most of the test points were executed using a test article flowrate of approximately $100 \mathrm{lb} / \mathrm{hr}$.

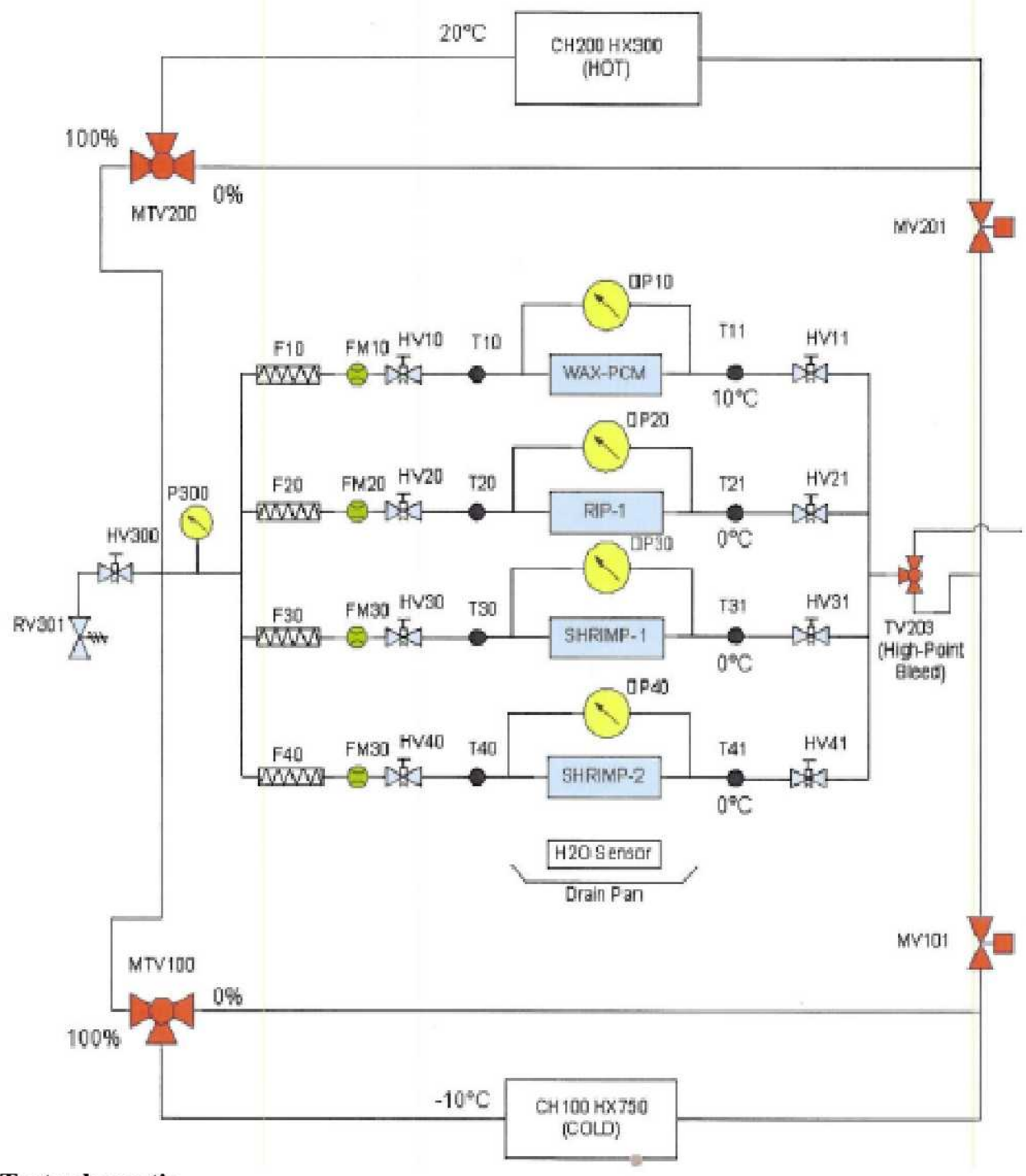

Figure 8. Test schematic.

Each test point began with an initial phase where the test article was cooled to $20 \mathrm{After}$ an isothermal temperature was achieved, the freeze cycle was started. Once an isothermal temperature was achieved throughout 
the test article (typically between $-4^{\circ} \mathrm{C}$ and $-8^{\circ} \mathrm{C}$ ) hot flow was started and the test article was again warmed to $20^{\circ} \mathrm{C}$. Again, after an isothermal temperature was achieved at $20^{\circ} \mathrm{C}$, the test cycle ended or was followed by another cold cycle.

Initial testing began with installing and testing the wax-PCM test article in each of the four test locations on the ice PCM cart. This was to verify proper instrumentation operation at each test location and also serve as a baseline for follow-on tests. Following wax-PCM testing, five cycles of RIP were completed. The SHRIMP's were the last test articles to be tested. Five freeze/thaw cycles were completed with both of the SHRIMP test article. These five cycles were followed by twenty favorable gravity cycles (PCM side up) and then by twenty adverse gravity cycles (PCM side down), for a total of 45 freeze/thaw cycles (see Table 2). Testing in adverse gravity conditions was completed in an effort to understand the impact on gravitational orientation. In a simplified manner, Figs. 9 and 10 how the difference in heat sink configuration between favorable and unfavorable gravity conditions in both SHRIMP test articles. Note the change in void space location between favorable and unfavorable gravity in SHRIMP-1 (assuming gravity dominates over capillary effects). It is assumed that the adverse gravity condition for SHRIMP-1 (which is the same as the bottom side of RIP) is the most challenging since freezing will occur from the top down, thereby separating the last remaining liquid from the void.

Table 2. Number of tests completed.

\begin{tabular}{|l|c|c|c|c|}
\hline & Wax-PCM & RIP & SHRIMP-1 & SHRIMP-2 \\
\hline Cycles & 4 & 5 & 45 & 45 \\
\hline
\end{tabular}

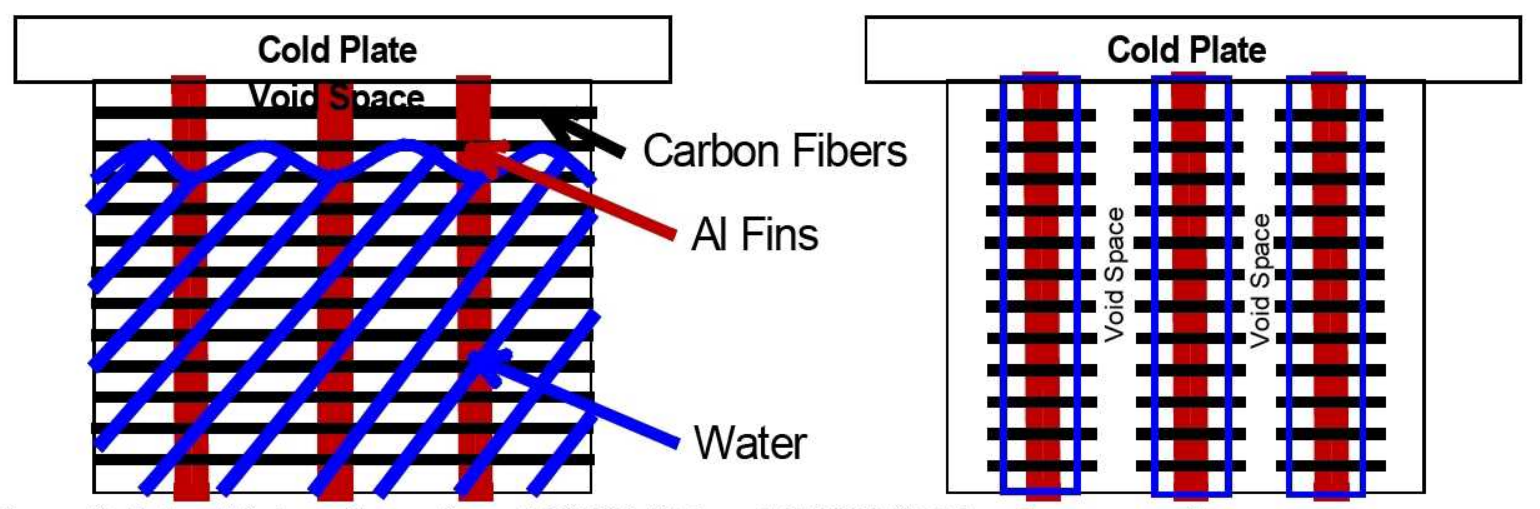

Figure 9. Interstitial configuration of SHRIMP-1 and SHRIMP-2 in adverse gravity.

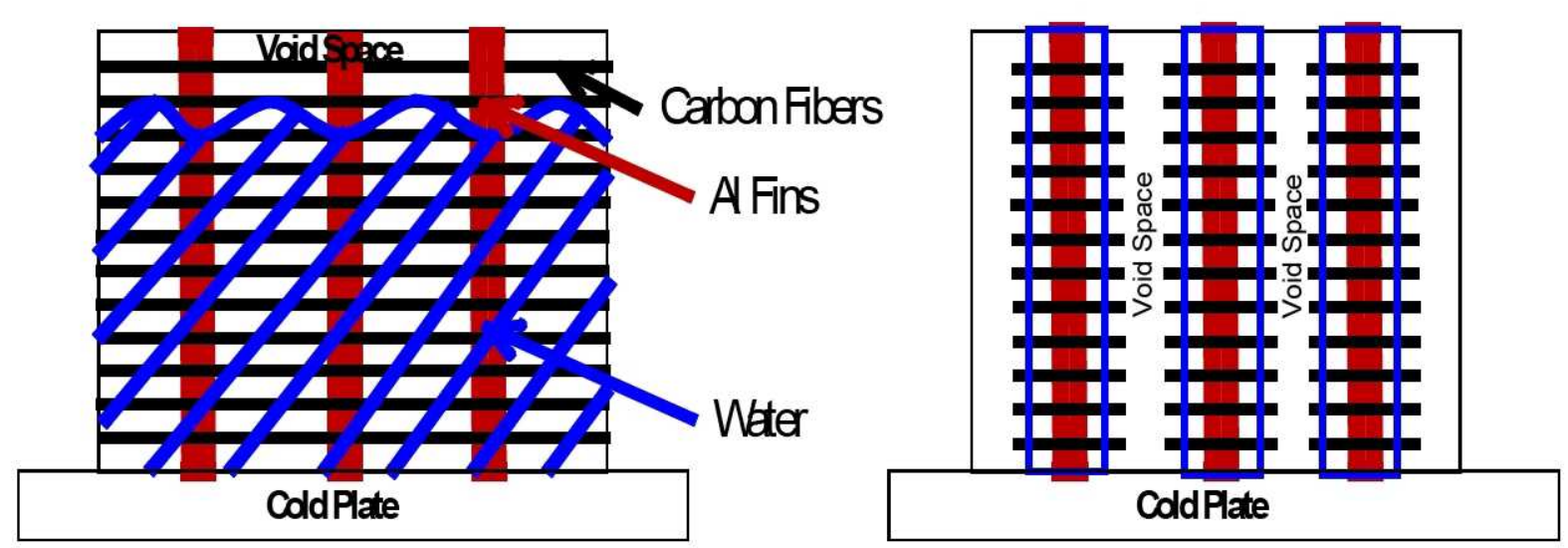

Figure 10. Interstitial configuration of SHRIMP-1 and SHRIMP-2 in favorable gravity 


\section{Analytical Process}

Analysis was focused on determining and verifying the expected latent energy storage for RIP and the SHRIMP test articles. The total energy either stored in or removed from the test article is simply the sum of the latent and sensible energy as shown in Equation 2. The total energy was calculated using the test cart instrumentation and is given by Equation 3. The sensible energy was calculated with knowledge of the materials included in the PCM heat exchanger and the temperature difference between hot and cold steady state operations as shown in Equation 4. It is important to note that there were several materials (aluminum, carbon fibercore, phase change material, etc...). With knowledge of the total energy stored/removed and the test article's sensible energy, the latent energy was calculated using Equation 2.

$$
E_{t}=E_{s}+E_{l}
$$

In the preceding equation:

$E_{t}$ represents the total energy stored/removed from the heat exchanger

$E_{s}$ represents the total sensible energy change during a test point

$\mathrm{E}_{1}$ represents the total latent energy change during a test point

$$
E_{t}=\int_{t_{o}}^{t_{f}} Q d t=\int_{t_{o}}^{t_{f}} \dot{m} C_{p}\left(T_{\text {in }}-T_{\text {out }}\right) d t
$$

In Equation 3:

$t_{o}$ represents the time at the beginning of the test point

$t_{\mathrm{f}}$ represents the time at the conclusion of the test point

$\mathrm{Q}$ represents the instantaneous heat rate into/from the heat exchanger

$\dot{m}$ represents the PGW flowrate into the heat exchanger

$\mathrm{C}_{\mathrm{p}}$ represents the specific heat of the PGW evaluated at the average of the heat exchanger inlet and exit temperature

$\mathrm{T}_{\mathrm{in}}$ represents the PGW temperature at the heat exchanger inlet

$\mathrm{T}_{\text {out }}$ represents the PGW temperature at the heat exchanger exit

$$
E_{s}=\sum_{i}^{N} m_{i} C_{p, i}\left(T_{\text {initial }, i}-T_{\text {final }, i}\right)
$$

In the preceding equation:

i represents one of the materials included in the heat exchanger (aluminum, carbon fibercore, phase change material, etc...)

$\mathrm{m}_{\mathrm{i}}$ represents the mass of the material being considered in the summation

$\mathrm{C}_{\mathrm{p}, \mathrm{i}}$ represents the specific heat of the material being considered in the summation

$\mathrm{T}_{\text {initial, } i}$ represents the initial temperature of the material being considered in the summation. This is the temperature of the material at the beginning of the freeze/thaw cycle

$\mathrm{T}_{\text {final, }, \mathrm{r}}$ represents the final temperature of the material being considered in the summation. This is the temperature of the material at the end of the freeze/thaw cycle.

It is important to note that the energy exchange with the ambient environment is not considered in the preceding analysis. A calculation was performed and the impact of this parasitic heat load was shown to be negligible.

\section{Testing Results}

Representative plots of temperature data are shown in Figs. 11 and 12 for fluid inlet and exit temperatures as well as heat exchanger surface temperatures. 


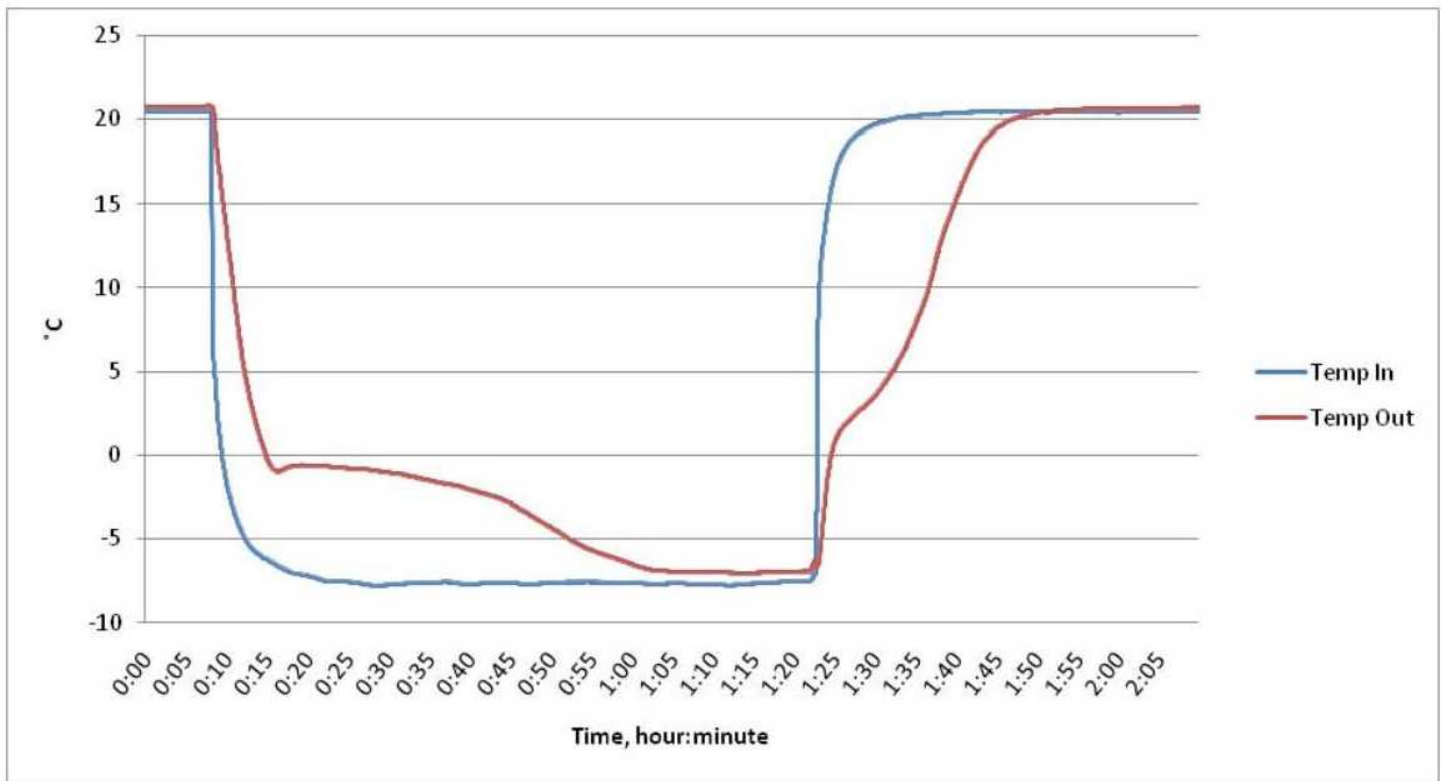

Figure 11. Representative plot of fluid inlet and outlet temperatures.

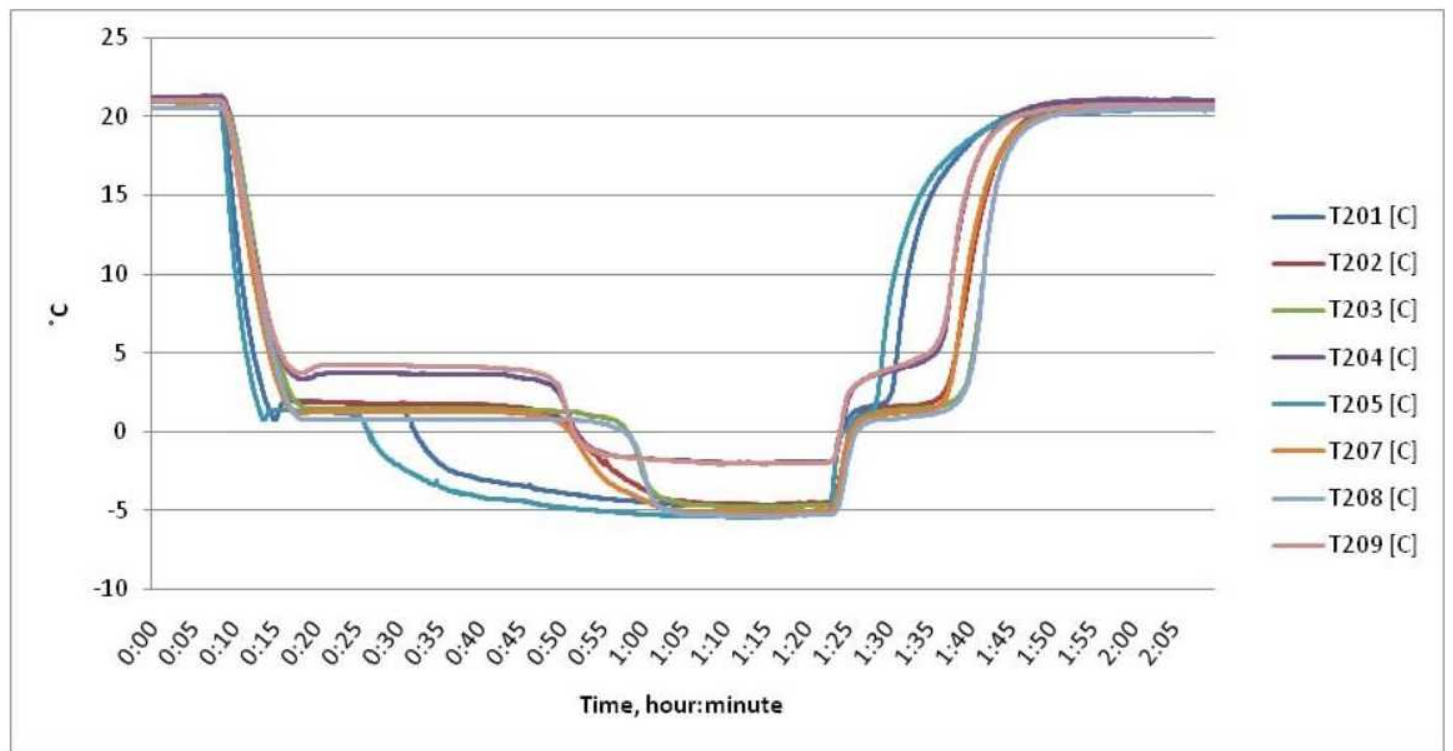

Figure 12. Representative plot of surface thermocouples.

A summary of energy storage data for RIP and both SHRIMP test articles for each cold and hot cycle can be found in Tables 3 and 4. These numbers represent the average across all of the freeze/thaw cycles for total, sensible, and latent energy storage or removal. The average latent energy storage for all RIP and SHRIMP tests is found in Fig. 13. 
Table 3. Cold (freezing) cycle energy storage.

\begin{tabular}{|lrrr|}
\hline \multicolumn{1}{l}{ Article (\# of Cycles) } & Et Storage (kJ) & Es Storage (kJ) & El Storage (kJ) \\
\hline RIP (5) & 764.87 & 241.92 & 522.95 \\
\hline SHRIMP-1 (5) & 140.85 & 78.48 & 62.37 \\
SHRIMP-1 (20 Favorable) & 152.87 & 79.68 & 71.66 \\
SHRIMP-1 (20 Adverse) & 161.18 & 82.86 & 78.67 \\
\hline SHRIMP-2 (5) & 144.23 & 75.40 & 68.83 \\
SHRIMP-2 (20 Favorable) & 130.69 & 80.35 & 50.67 \\
SHRIMP-2 (20 Adverse) & 144.96 & 82.42 & 62.23 \\
\hline
\end{tabular}

Table 4. Hot (melting) cycle energy storage.

\begin{tabular}{|lrrr|}
\hline \multicolumn{1}{l}{ Article (\# of Cycles) } & Et Storage (kJ) & Es Storage (kJ) & El Storage (kJ) \\
\hline RIP (5) & 629.33 & 231.92 & 397.41 \\
\hline SHRIMP-1 (5) & 128.90 & 76.78 & 52.12 \\
SHRIMP-1 (20 Favorable) & 117.40 & 78.25 & 36.42 \\
SHRIMP-1 (20 Adverse) & 115.46 & 79.67 & 35.99 \\
\hline SHRIMP-2 (5) & 120.32 & 74.06 & 46.27 \\
SHRIMP-2 (20 Favorable) & 132.71 & 77.44 & 55.27 \\
SHRIMP-2 (20 Adverse) & 131.53 & 76.11 & 51.93 \\
\hline
\end{tabular}

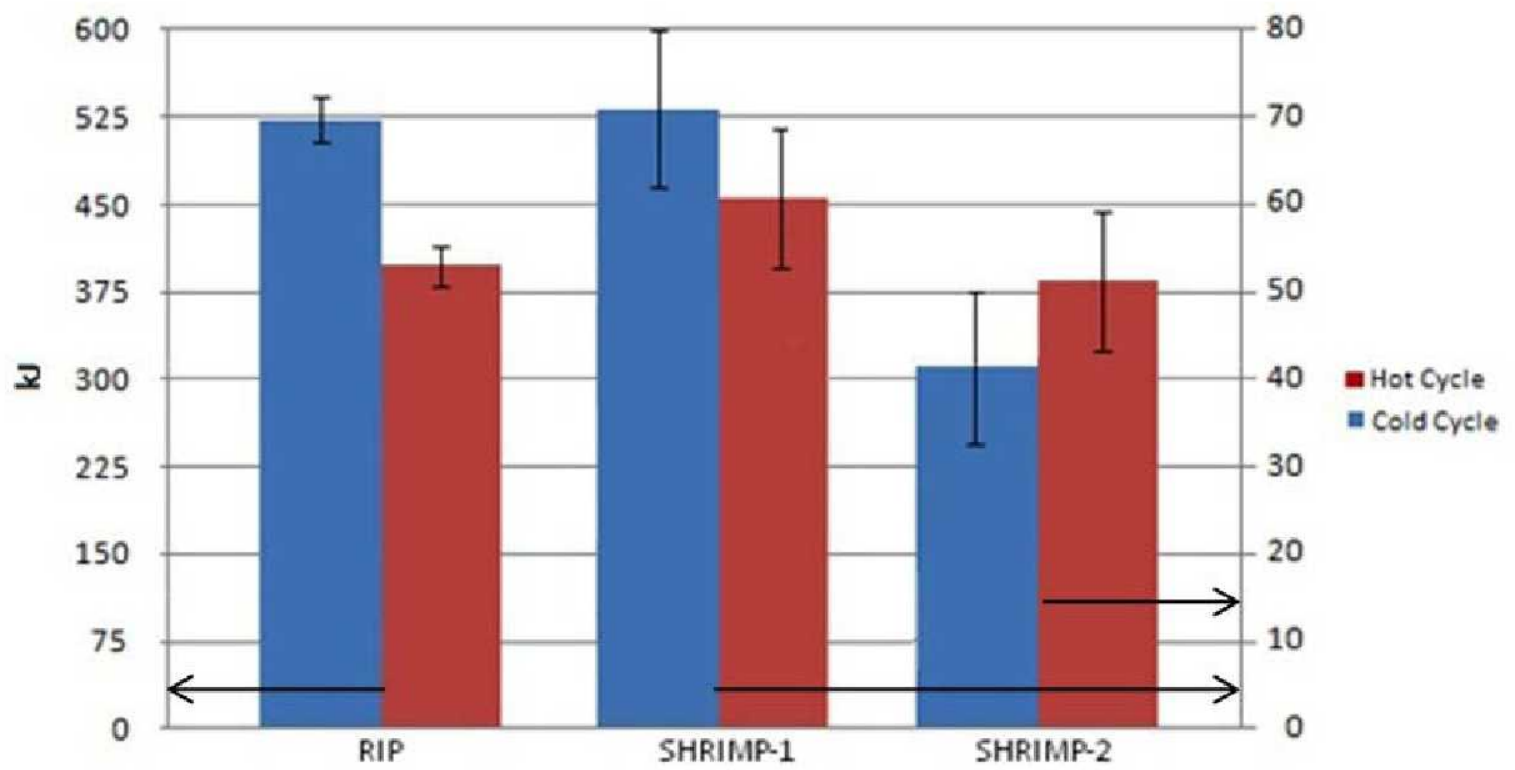

Figure 13. RIP and SHIMP total latent energy storage. 
Using knowledge of the phase change material mass, which is 1360 grams for RIP and 120 grams for each of the SHRIMP test articles, and water's heat of fusion the expected latent energy storage was calculated. For RIP, the expected latent energy storage is approximately $450 \mathrm{~kJ}$. Because the SHRIMP test articles had much less phase change material mass, the expected latent energy storage was only $40 \mathrm{~kJ}$. As shown in Fig. 13, these values agree fairly well with the calculated latent energy storage. The differences can be attributed to experimental errors which were calculated to be approximately $5 \%$ for RIP and $15-20 \%$ SHRIMP.

\section{Test Article Damage}

During the testing process, various inspections were made to each test article. Each article experienced some type of damage during testing. RIP was inspected after the second, fourth, and fifth cycles, with damage being discovered after the second cycle and more extensive damage being discovered after the fourth cycles. The pictures in Figs. 14 and 15 were taken after the fifth and final cycle of RIP. The outlined markings on the PCM indicate bulges in the test article. Note that the locations of the damage are mostly around the outer edges, corresponding to the no-flow regions around the edge of the coldplate, and along the coolant exit side of the U-shaped flow path through the coldplate. This pattern indicates that freezing occurred directionally from the coldest regions to the warmest regions. Project personnel have hypothesized that as freezing was occurring, remaining liquid water was getting pushed toward these warmer regions, filling the remaining voids with liquid water. When the last of the liquid water froze, it no longer had access to sufficient void space, and pushed out on the metal housing, resulting in the observed bulging.

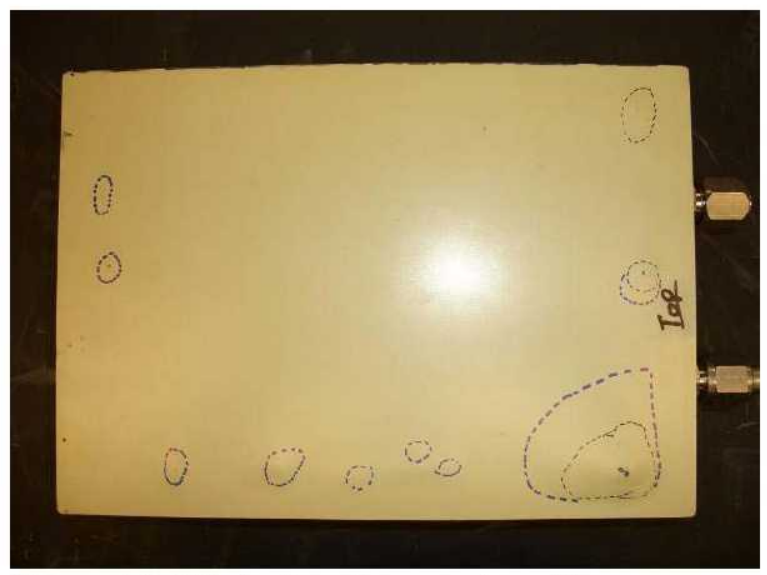

Figure 14. RIP testing damage, top side.

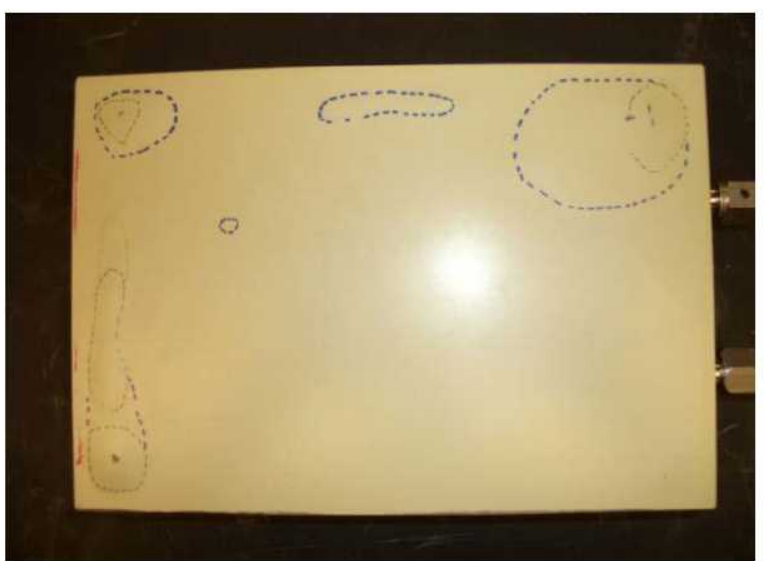

Figure 15. RIP testing damage, bottom side.

SHRIMP-1 and SHRIMP-2 were inspected after the fifth and twenty-fifth favorable gravity cycles and no surface damage was noticed. As stated above, subsequent tests were performed in an adverse gravity orientation (i.e. PCM 
located on the underside of the coldplate). The heat exchangers were inspected after the first, fourth, and twentieth adverse gravity cycles. Damage was found in SHRIMP-1 after the first adverse gravity cycle and further damage was found after the twentieth adverse gravity cycle. No damage was found on SHRIMP-2 after the first and fourth adverse gravity cycles, but damage was found on SHRIMP-2 after the twentieth adverse gravity cycle. The observed damage is outlined in Figs. 16 and 17 for SHRIMP-1 and Fig. 18 for SHRIMP-2. For the SHRIMP test articles, the location of the bulging is in the middle, which corresponds to the no-flow region in the middle of the coldplate. This indicates that freezing occurred directionally from the perimeter of the phase change material to the middle of the module. The current hypothesis for this failure mode is the same as RIP. Project personnel suspect that remaining liquid water was pushed into the voids in the middle of the unit. Having insufficient void space left for expansion, the last remaining water to freeze pushed out on the metal housing, resulting in the observed bulging. The damage to SHRIMP-2 is minimal as compared to SHRIMP-1, indicating that the arrangement of the interstitial material in SHRIMP-2 did provide some improvement in maintaining the voids and the water was likely distributed more uniformly.

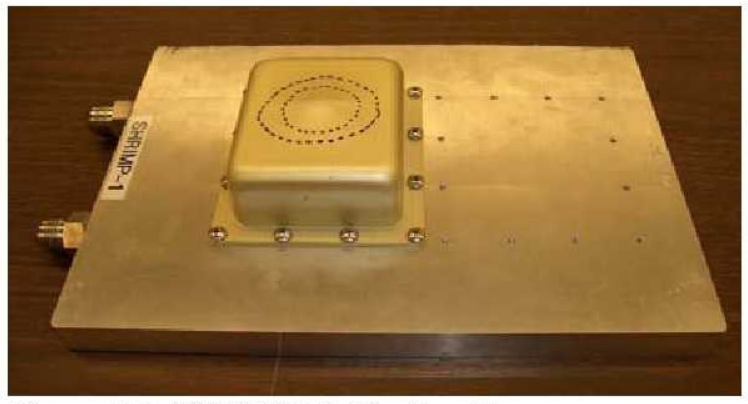

Figure 16: SHRIMP-1, Testing Damage.

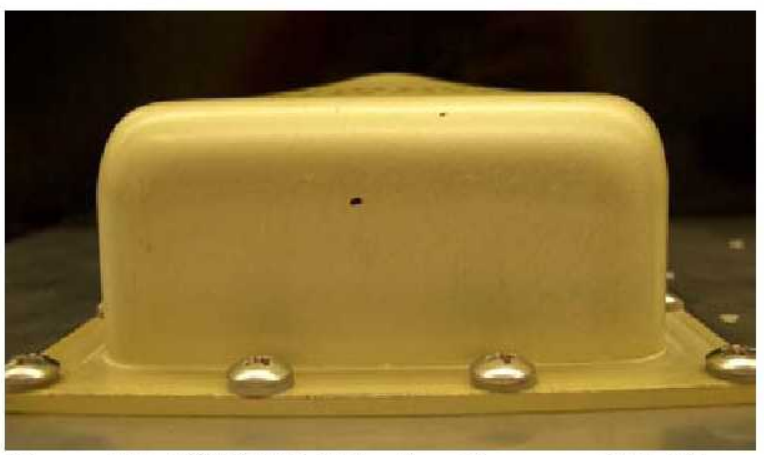

Figure 17: SHRIMP-1 Testing Damage, Side View.

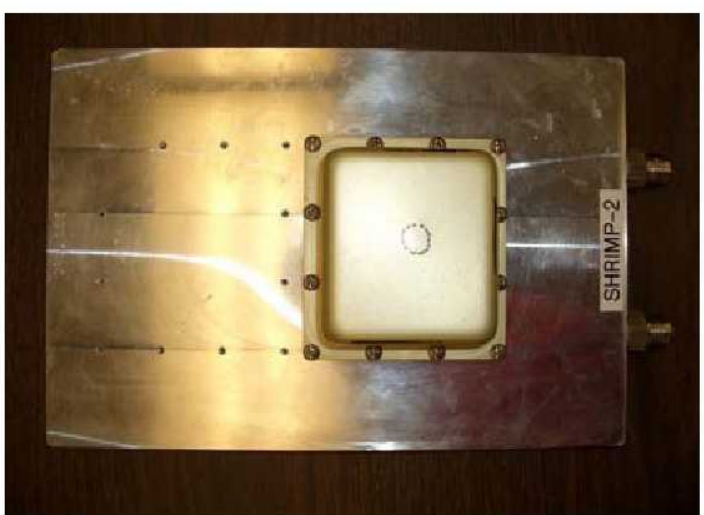

Figure 18. SHRIMP-2 Testing Damage. 
Table 5 summarizes the observations of damage for the three test articles. It is not surprising that SHRIMP-1 in an adverse gravity condition and the bottom of RIP both showed consistent results on the early freeze/thaw cycles. It is not clear why the top side of RIP showed damage early but SHRIMP-1 in a favorable gravity orientation showed no damage even after 25 cycles. One hypothesis is that the smaller size of SHRIMP-1 did not provide as much room for liquid water to get pushed around due to directional freezing. It appears that the arrangement of interstitial material in SHRIMP-2 does provide improved void location control and resistance to damage, although there is still room for improvement.

Table 5. Cycles and damage correlation.

\begin{tabular}{|l|c|c|c|}
\hline \multicolumn{4}{|c|}{ Number of cycles until damage } \\
\hline Orientation & RIP & SHRIMP-1 & SHRIMP-2 \\
\hline Favorable (top) & $\leq 2$ & $\begin{array}{c}\text { No damage } \\
\text { after 25 cycles }\end{array}$ & $\begin{array}{c}\text { No damage } \\
\text { after 25 cycles }\end{array}$ \\
\hline Adverse (bottom) & $\leq 2$ & 1 & $\leq 20$ \\
\hline
\end{tabular}

VII. Future Plans

The project is planning to continue evaluating the development of ice phase change material heat exchangers. To that end, project personnel have decided to develop an additional five heat exchangers. A brief description of these heat exchangers and their intended purpose is described below:

1.) HS-01: Half of RIP on a second generation coldplate

- This heat exchanger is similar to the previously developed RIP test article. The first difference is that the PCM module will only be located on a single side of the coldplate. This configuration will allow the project to test a larger heat exchanger in both favorable and adverse gravity orientations. A second difference is in the coldplate. The coldplate will still be an off-the-shelf coldplate, but will be designed to be a single pass coldplate rather than the "u-shaped" coldplate included in the current RIP design. This new configuration will eliminate the no-flow regions of the "u-shaped" coldplate and, as a result, will provide a more uniform heat flux.

2.) HS-02: Four SHRIMP PCM modules on a first generation coldplate

- This heat exchanger includes the same off-the-shelf coldplate used for the existing heat exchangers. The difference is that the coldplate will be coupled with a two by two array of four smaller PCM modules. These smaller modules will be the same configuration as SHRIMP-1. This unit will be used to make two comparisons with the existing hardware. This configuration is similar to RIP except the PCM module is divided into four smaller containers. As a result, the project will be able to investigate any issues associated with the size of the PCM module. Additionally, the performance of this hardware will be compared to the existing SHRIMP-1 unit. The primary difference will be the location of the small PCM modules relative to the flowing and no-flow regions of the coldplate. It is anticipated that any damage to this unit would not necessarily be located in the middle like it was for the current SHRIMP test articles.

3.) HS-03: Four SHRIMP PCM modules on a second generation coldplate

- This heat exchanger is the same as the previous heat exchanger. The "u-shaped" coldplate will be replaced with a single pass coldplate similar to HS-01. The performance of this unit will be directly compared with the previous heat exchanger. Specifically, project personnel will be focused on the location of any damage and how it relates to directional freezing.

4.) HS-04: Second generation RIP on a first generation coldplate

- This heat exchanger is a full-size unit $(450 \mathrm{~kJ})$ with PCM modules located on both sides of the "ushaped" coldplate. The PCM module will include the same interstitial arrangement as the current SHRIMP-2 test article. This heat exchanger will be used to assess whether the SHRIMP-2 architecture will be equally effective at larger scales.

5.) HS-05: Second generation RIP on a first generation coldplate including gel 
- This heat exchanger is the same as HS-04 except a gel substance is added to the water. This gel substance is advertised to enhance the ability of the fibers to wick and "hold on" to the water. The latent energy will be calculated to evaluate whether the addition of the gel reduces the latent energy storage of the heat exchanger.

\section{Conclusions}

The previously described test program was successful on several levels. A robust cart capable of testing a wide range of PCM heat exchangers was designed and fabricated. Using this test cart, project personnel evaluated the performance for one existing and three new heat exchangers. Furthermore, this task demonstrated that using water as a phase change material is a viable option provided issues associated with expansion of ice can be addressed. The use of water can result in significant mass and volume savings. A simple gap by itself may not be sufficient to handle the expansion unless the location of the void(s) can be intelligently controlled. In addition to these lessons, the project has identified an additional five test articles that will help to validate theories explaining why the

previous test articles experienced structural integrity issues. The project will design, fabricate, and test these next generation ice PCM heat exchangers.

\section{Acknowledgements}

The authors would like to thank Timothy Knowles and Mike Carpenter at Energy Science Laboratories, Inc. (ESLI) for fabricating the test articles for this investigation and for sharing their expertise and insight into the design and operation of these phase change material heatsinks.

\section{References}

${ }^{1}$ Lillibridge, S., Stephan, R., "Phase Change Material Heat Exchanger Life Test," SAE Paper 2009-01-2589, 39th International Conference on Environmental Systems (ICES), Savannah, GA, July 2009. 